\title{
Artifactual hypoglycemia in a patient with sickle cell anemia
}

\author{
Linda R. Wang MD, Justin Morein MD, Christopher McCudden PhD, Alexander Sorisky MDCM
}

Cite as: CMAJ 2021 November 1;193:E1660-2. doi: 10.1503/cmaj.210191

A 53-year-old woman was referred to the endocrinology clinic for recurrent hypoglycemia detected on bloodwork. The patient's fasting serum glucose values over the previous year ranged from 2.6 to $3.4 \mathrm{mmol} / \mathrm{L}$. Although asymptomatic, she was given juice as treatment each time the result was reported.

She had homozygous sickle cell disease with complications, systemic lupus erythematosus, multiple sclerosis, optic neuritis and bladder dysfunction. She did not have diabetes mellitus and was not using hypoglycemic agents. Her medications included prednisone ( $5 \mathrm{mg} / \mathrm{d}$, stable dose for $2 \mathrm{yr}$ ), azathioprine, desmopressin, folic acid, vitamin $\mathrm{D}$, vitamin $\mathrm{B}_{12}$, olmesartan, tolterodine, gabapentin and calcium supplements. She had been receiving exchange transfusions every 8 weeks, with preexchange hemoglobin $\mathrm{S}$ levels consistently above $50 \%$; the frequency of exchange transfusions had been reduced from every 4 weeks at the patient's request about 1 year before. She had no family history of endocrine neoplasia or diabetes.

Because the patient reported no symptoms of hypoglycemia, we were suspicious that the recorded glucose values were falsely low. We noted that the previous venous blood samples were all drawn before exchange transfusions when massive reticulocytosis was present (reticulocyte count as high as 401.5 [normal range $22-92] \times 10^{9} / \mathrm{L}$ ). This suggested the possibility of excessive glucose consumption by the metabolically active reticulocytes in the test tube before laboratory analysis could be conducted.

We asked the patient to self-measure capillary glucose values twice daily for 2 weeks (fasting and postprandial timing); she had normal glucose values that ranged from 3.9 to $5.1 \mathrm{mmol} / \mathrm{L}$. In addition, when we measured whole blood glucose on a blood gas

Box 1: Blood glucose test results for a 53-year-old woman with sickle cell anemia, by method of measurement

\begin{tabular}{lc} 
Method & Result, $\mathbf{~ m m o l} / \mathbf{L}$ \\
$\begin{array}{l}\text { Venous blood sample without an inhibitor of } \\
\text { glycolysis (multiple measurements) }\end{array}$ & $2.6-3.4$ \\
\hline $\begin{array}{l}\text { Capillary blood sample (twice daily over } 2 \text { wk) } \\
\text { Fasting whole blood sample using a blood gas analyzer }\end{array}$ & $3.9-5.1$ \\
\hline $\begin{array}{l}\text { Fasting venous blood sample collected in a tube } \\
\text { containing sodium fluoride }\end{array}$ & 4.8 \\
\hline
\end{tabular}

\section{Key points}

- Patients with markedly elevated levels of nucleated blood cells, such as leukocytes or reticulocytes, may have artifactually low serum blood glucose measurements due to excessive glucose consumption by cells in the sample tube before laboratory analysis.

- In such patients, blood glucose can be more accurately measured by using finger-prick capillary glucose testing, processing of the sample within 30 minutes or using tubes that contain an inhibitor of glycolysis.

- A true hypoglycemic event generally reflects Whipple triad: low serum glucose, with hypoglycemic symptoms at the time of the sample draw showing low glucose, and resolution of symptoms after appropriate treatment of low glucose.

- Low blood glucose levels in the absence of autonomic and neuroglycopenic symptoms of hypoglycemia should raise suspicion for artifactual hypoglycemia, and glucose should be assessed using an alternative modality before further resourceintensive diagnostic investigations are undertaken.

analyzer (which minimizes delay between blood collection in the tube and subsequent analysis) and on a blood sample collected in a tube containing sodium fluoride/potassium oxalate (an inhibitor of glycolysis) we recorded normal fasting glucose levels of 4.6 and $4.8 \mathrm{mmol} / \mathrm{L}$, respectively (Box 1 ). The prereferral samples that yielded hypoglycemic readings were collected in tubes that did not contain an inhibitor of glycolysis. All 3 methods were performed in the presence of massive reticulocytosis $\left(481.6 \times 10^{9} / \mathrm{L}\right.$ during capillary glucose testing and $594.6 \times 10^{9} / \mathrm{L}$ at time of blood draw [normal range $22-92 \times 10^{9} /$ L]).

We advised the patient and her doctors that she did not have true hypoglycemia and did not require further resource-intensive investigation and monitoring. If glucose measurements were deemed necessary when reticulocytes were high, we advised using 1 of the methods described above, the most practical being point-of-care capillary glucose measurement.

\section{Discussion}

True hypoglycemia in patients without diabetes mellitus is uncommon. Thorough investigation is required to differentiate between such uncommon causes as endogenous hyperinsulinism, non-islet 
cell tumours, adrenal insufficiency, critical illness, sepsis, organ failure, severe malnutrition and adverse effects from drugs such as gatifloxacin and indomethacin. ${ }^{1}$ However, a crucial first step before ordering tests is to determine whether a low glucose measurement reflects true hypoglycemia.

\section{Whipple triad}

A true hypoglycemic event is defined by Whipple triad: symptoms or signs of hypoglycemia such as autonomic and neuroglycopenic symptoms, low concentration of blood glucose at the time of symptoms and resolution of symptoms after the blood glucose level is raised. ${ }^{1}$

Autonomic symptoms of hypoglycemia include tremor, palpitations, sweating, hunger, anxiety and paresthesias. Neuroglycopenic symptoms include weakness, confusion, behavioural changes, decreased level of consciousness and seizure. ${ }^{1}$

\section{Artifactual hypoglycemia}

In patients without a reason for unawareness of hypoglycemaia (such as long-standing diabetes), a low blood glucose level without symptoms should raise suspicion of artifactual hypoglycemia. Measurement of blood glucose should be performed using an alternate method before more extensive investigations are ordered.

Typically, venous blood glucose is relied upon to confirm hypoglycemia found on point-of-care capillary testing. However, this case illustrates that venous blood glucose testing can produce erroneously low values in certain circumstances. Each method of evaluation is susceptible to its own errors (Box 2), and awareness of the limitations of each allows clinicians to choose the most suitable test to confirm an unexpected result.

Preanalytical errors are important yet under-recognized causes of falsely low measurements for venous blood glucose, the most common of which is in vitro glycolysis by metabolically active cells between the time of blood collection and subsequent laboratory analysis. The American Diabetes Association recommends placing samples in ice slurry and separating plasma from cells within 30 minutes to minimize glycolysis; ${ }^{10}$ however, this is not always achievable in practice. The importance of this phenomenon was highlighted by a 2020 study in Australia that evaluated the processing of samples for oral glucose tolerance tests (75 g) that were taken from women who were pregnant and being screened for gestational diabetes; with an early centrifugation protocol, rates of diagnosis of gestational diabetes increased from $11.6 \%$ to $20.6 \%$, illustrating the important public health impacts of preanalytical processes. ${ }^{11}$

\section{Impact of metabolically active cells}

An excess of nucleated cells can exaggerate in vitro glycolysis, and the degree of artifactual hypoglycemia can be enough to cause alarm. Artifactual hypoglycemia caused by this mechanism is seen classically in patients with extreme leukocytosis, such as in leukemia. ${ }^{2}$ In our patient, however, the cause was likely massive reticulocytosis caused by sickle cell disease. This has been rarely reported as a cause of artifactual hypoglycemia in patients with other conditions such as polycythemia vera and chronic hemolytic anemia.,12

The prevalence of this artifact in patients with sickle cell disease is difficult to estimate, as measurements of blood glucose are not routinely indicated in sickle cell disease. The request for blood glucose testing was ordered initially by our patient's nephrologist when investigating her mild proteinuria and was repeated regularly because of the persistently abnormal result.

The severity of the underlying reticulocytosis affects the degree to which this artifact is observed. Considerable variation exists in the severity of sickle cell disease, both across genotypes and within each genotype. Our patient had a severe genotype ( $H b S S$ ) and phenotype of sickle cell anemia with several complications. The low glucose measurements occurred after lengthening the interval between exchange transfusions from 4 to 8 weeks, resulting in levels of hemoglobin $\mathrm{S}$ of over $50 \%$ pre-exchange

Box 2: Commonly encountered sources of artifacts in measurements of blood glucose

\begin{tabular}{|c|c|c|}
\hline Measurement method & Reason for falsely low blood glucose & Reason for falsely elevated glucose \\
\hline Capillary glucose & 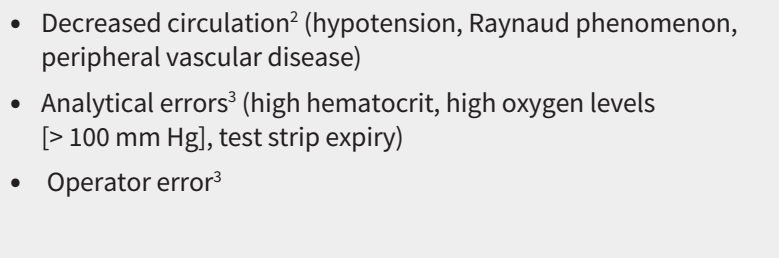 & $\begin{array}{l}\text { - Sugary substances on skin }{ }^{3} \\
\text { - Low hematocrit } \\
\text { - Icodextrin-containing peritoneal dialysis } \\
\text { - } \text { solutions }^{3 \star} \\
\text { - High uric acid levels }{ }^{3 *} \\
\text { - Low oxygen levels }{ }^{3}\end{array}$ \\
\hline Venous glucose & $\begin{array}{l}\text { - Leukocytosis }{ }^{1,2} \text { (leukemia, }^{2} \text { reactive leukocytosis }{ }^{4} \text { ) } \\
\text { - Reticulocytosis }{ }^{1,2} \text { (polycythemia vera, }{ }^{2,5} \text { chronic hemolytic anemia }{ }^{6} \text { ) } \\
\text { - Prolonged delay in transport or analysis }{ }^{1} \\
\text { - Hyperviscosity }{ }^{2}\end{array}$ & \\
\hline $\begin{array}{l}\text { Subcutaneous glucose } \\
\text { monitor }\end{array}$ & $\begin{array}{l}\text { - } \text { Local compression }^{7} \\
\text { - Presence of salicylic acid } \\
\text { - First } 12 \text { h of new sensor }\end{array}$ & $\begin{array}{l}\text { - Acetaminophen }{ }^{9 *} \\
\text { - Hydroxyurea } \\
\text { - }{\text { Vitamin } \mathrm{C}^{8}}^{9}\end{array}$ \\
\hline
\end{tabular}


(target $<30 \%$ ), and the low glucose measurements had been recorded before exchanges, at the peak of reticulocytosis.

\section{Methods to mitigate excessive in vitro glycolysis}

In the presence of markedly elevated nucleated cells, the most accurate methods for measurement of glucose are those that minimize the delay between blood collection and analysis, such as point-of-care capillary blood glucose or venous blood gas analysis (analyzed within 5-10 min). Sample tubes that contain an inhibitor of glycolysis may also allow for more accurate results by reducing in vitro consumption of glucose. ${ }^{11,12}$ Newer inhibitors of glycolysis such as citrate are associated with a more accurate glucose result than fluoride but are not as widely available. ${ }^{6}$

We used all of these suggested methods to clarify that the low venous blood glucose levels initially reported for our patient were artifactual, preventing further unnecessary and resource-intensive investigations. Artifactually low serum glucose should be considered in patients without symptoms of hypoglycemia before undertaking an extensive workup for true hypoglycemia.

\section{References}

1. Cryer PE, Axelrod L, Grossman AB, et al.; Endocrine Society. Evaluation and management of adult hypoglycemic disorders: an Endocrine Society clinical practice guideline. J Clin Endocrinol Metab 2009;94:709-28.

2. Tarasova VD, Zena M, Rendell M. Artifactual hypoglycemia: an old term for a new classification. Diabetes Care 2014;37:e85-6.

3. Ginsberg BH. Factors affecting blood glucose monitoring: sources of errors in measurement. J Diabetes Sci Technol 2009;3:903-13.

4. Cryer P. Glucose homeostasis and hypoglycemia. In: Kronenberg H, Melmed S, Polonsky K, et al., editors. Williams textbook of endocrinology. 11th ed. Philadelphia: Saunders;2008:1503-33.

5. Macaron Cl, Kadri A, Macaron Z, et al. Nucleated red blood cells and artifactual hypoglycemia. Diabetes Care 1981;4:113-5.

6. Gambino R, Bruns DE. Stabilization of glucose in blood samples: out with the old, in with the new. Clin Chem Lab Med 2013;51:1883-5.

7. Mensh BD, Wisniewski NA, Neil BM, et al. Susceptibility of interstitial continuous glucose monitor performance to sleeping position. J Diabetes Sci Technol 2013;7:863-70.

8. Freestyle Libre 14 day indications and important safety information. Chicago: Abbott Laboratories. Available: https://provider.myfreestyle.com/safety -information.html (accessed 2021 May 30).

9. Interfering substances and risks. Dexcom. Available: https://www.dexcom. com/interference (accessed 2021 May 30).
10. Sacks DB, Arnold M, Bakris GL, et al.; National Academy of Clinical Biochemistry. Position statement executive summary: guidelines and recommendations for laboratory analysis in the diagnosis and management of diabetes mellitus. Diabetes Care 2011;34:1419-23.

11. Potter JM, Hickman PE, Oakman C, et al. Strict preanalytical oral glucose tolerance test blood sample handling is essential for diagnosing gestational diabetes mellitus. Diabetes Care 2020;43:1438-41.

12. Arem R, Jeang MK, Blevens TC, et al. Polycythemia rubra vera and artifactual hypoglycemia. Arch Intern Med 1982;142:2199-201.

\section{Competing interests: None declared.}

This article has been peer reviewed.

The authors have obtained patient consent.

Affiliations: Division of Endocrinology and Metabolism, Department of Medicine (Wang, Morein, Sorisky), The Ottawa Hospital and University of Ottawa; Department of Pathology and Laboratory Medicine (McCudden), The Ottawa Hospital and University of Ottawa; Eastern Ontario Regional Laboratory Association (McCudden); Ottawa Hospital Research Institute (Sorisky), The Ottawa Hospital, Ottawa, Ont.

Contributors: Linda Wang and Alexander Sorisky developed the concept of the report. All of the authors drafted the work and revised it critically for important intellectual content, gave final approval of the version to be published and agreed to be accountable for all aspects of the work.

Content licence: This is an Open Access article distributed in accordance with the terms of the Creative Commons Attribution (CC BY-NC-ND 4.0) licence, which permits use, distribution and reproduction in any medium, provided that the original publication is properly cited, the use is noncommercial (i.e., research or educational use), and no modifications or adaptations are made. See: https://creativecommons.org/licenses/by-nc-nd/4.0/

Correspondence to: Alexander Sorisky, asorisky@toh.ca

The section Cases presents brief case reports that convey clear, practical lessons. Preference is given to common presentations of important rare conditions, and important unusual presentations of common problems. Articles start with a case presentation (500 words maximum), and a discussion of the underlying condition follows (1000 words maximum). Visual elements (e.g., tables of the differential diagnosis, clinical features or diagnostic approach) are encouraged. Consent from patients for publication of their story is a necessity. See information for authors at www.cmaj.ca. 